\title{
Properties of Some Norvaline-resistant Mutants of Bacillus subtilis
}

\author{
By W. D. HOLTZCLAW AND LINDA F. CHAPMAN \\ Division of Biological Sciences, University of Missouri, \\ Columbia, Missouri 65201, U.S.A.
}

(Received 21 October 1974; revised 9 December 1974)

\begin{abstract}
SUMMARY
DL-Norvaline inhibits growth of wild-type Bacillus subtilis. A number of mutants resistant to growth inhibition by this analogue were isolated and studied. Cross-feeding experiments and paper chromatography of culture supernatants indicated that the mutants excreted leucine and possibly valine and glutamate. Enzymic analysis indicated that the mutants were derepressed for acetohydroxyacid synthetase and $\alpha$-isopropylmalate synthetase; however, no derepression of threonine deaminase, dihydroxyacid dehydrase or transaminase B was observed.
\end{abstract}

\section{INTRODUCTION}

An important aid in the study of the control of biosynthetic pathways in micro-organisms has been the ability to isolate mutants having defective regulatory mechanisms. Such strains can often be obtained by selecting for mutants resistant to growth inhibition by analogues of pathway end-products. Several analogues have been successfully used to obtain regulatory mutants of the isoleucine, valine and leucine biosynthetic pathways. Calvo, Freundlich \& Umbarger (1969) isolated a number of Salmonella typhimurium mutants resistant to the analogue $5^{\prime}, 5^{\prime}, 5^{\prime}$-trifluoroleucine. One class of mutants excreted leucine and possessed an $\alpha$-isopropylmalate synthetase insensitive to inhibition by leucine. A second class of mutants excreted leucine and had derepressed levels of the leucine biosynthetic enzymes. The mutation mapped to one side of the leucine operon. A third class of mutants excreted isoleucine, valine and leucine and exhibited elevated levels of all of the branched-chain amino acid biosynthetic enzymes. Several mutants of Escherichia coli resistant to 4-thioisoleucine were obtained by Szentirmai, Szentirmai \& Umbarger (1968). These strains had derepressed levels of threonine deaminase, dihydroxyacid dehydrase and transaminase $\mathrm{B}$, but not of acetohydroxyacid synthetase or the isomeroreductase. These mutants appeared to possess an altered isoleucyl tRNA synthetase.

We describe strains of Bacillus subtilis resistant to DL-norvaline which show alterations in the regulation of several branched-chain amino acid biosynthetic enzymes.

\section{METHODS}

Strains. The wild-type strain of Bacillus subtilis used was WB746 (Chapman, 1972). The various derivatives of this strain were: NV20, NV26, NV35 and NV45-resistant to growth inhibition by $200 \mu \mathrm{g}$ DL-norvaline/ml; SB27I - requires leucine; SB377R - requires isoleucine and valine; SB7 - requires isoleucine.

Growth. Liquid cultures were grown in $250 \mathrm{ml}$ of medium as described by Chapman 
(I972) and Chapman \& Hull (I974). The cells were harvested by centrifugation, washed once with $0.05 \mathrm{M}$-potassium phosphate $\mathrm{pH} 7.0+0.5 \mathrm{mM}-\mathrm{MgCl}_{2}+0.0 \mathrm{I} \mathrm{mM}-\mathrm{MnCi}_{2}$, and stored frozen until use. Cells to be used for the assay of $\alpha$-isopropylmalate synthetase were washed with $0.05 \mathrm{M}$-tris $\mathrm{pH} 7 \cdot 4+\mathrm{I} \cdot 0 \mathrm{mM}-\alpha$-ketoisovalerate $+0 . \mathrm{I} \mathrm{mM}-\mathrm{MnCl}_{2}+20 \%(\mathrm{v} / \mathrm{v})$ glycerol.

Preparation of crude extracts. This was usually done by lysing the cells in a buffer containing $\mathrm{I} \cdot 0 \mathrm{mg}$ lysozyme and Io $\mu \mathrm{g}$ DNAase $/ \mathrm{ml}$ for $30 \mathrm{~min}$ at $37^{\circ} \mathrm{C}$ (for threonine deaminase assays, cells were lysed for $60 \mathrm{~min}$ at room temperature). Cell debris was removed by centrifugation at $27000 \mathrm{~g}$ for $30 \mathrm{~min}$ at 0 to $5{ }^{\circ} \mathrm{C}$ (for threonine deaminase, centrifugation was at room temperature). For acetohydroxyacid synthetase, the lysis buffer contained $0.05 \mathrm{M}$-potassium phosphate $\mathrm{pH} 7.0+0.05 \mathrm{M}-\mathrm{KCl}+5 \mathrm{mM}-\mathrm{MgCl}_{2}+80 \mu \mathrm{g}$ thiamine pyrophosphate (TPP) $/ \mathrm{ml}+\mathrm{I} 0 \mu \mathrm{g} \mathrm{FAD} / \mathrm{ml}$. For threonine deaminase and transaminase $\mathrm{B}$ the buffer was $0.05 \mathrm{M}$-potassium phosphate $\mathrm{pH} 7.0+0 . \mathrm{I}$ mM-pyridoxal-5-phosphate $+2 \mathrm{mM}-\mathrm{MgCl}_{2}$. For dihydroxyacid dehydrase the buffer was the same except pyridoxal phosphate was omitted. For $\alpha$-isopropylmalate synthetase the lysis buffer was the same as the wash buffer described above. Before use, the crude extract was filtered through a column of Sephadex G-25 at o to $5{ }^{\circ} \mathrm{C}$ and equilibrated with the same buffer without $\alpha$-ketoisovalerate.

Enzyme assays. Acetohydroxyacid synthetase was assayed by the method of Bauerle et al. (1964) and acetoin determined by the method of Westerfield (1945). The reaction mixture contained (per I.० $\mathrm{ml}$ ): I00 $\mu \mathrm{mol}$ potassium phosphate $\mathrm{pH} 8 \cdot 0 ; 20 \mu \mathrm{mol}$ pyruvate; Io $\mu \mathrm{mol}$ $\mathrm{MgCl}_{2} ; 80 \mu \mathrm{g}$ TPP; $20 \mu \mathrm{g}$ FAD. For controls, enzyme was added after termination of the reaction with $\mathrm{H}_{2} \mathrm{SO}_{4}$. Threonine deaminase was assayed by the method of Hatfield \& Umbarger (197I). The reaction mixture contained (per I $\cdot 0 \mathrm{ml}$ ) $: 100 \mu \mathrm{mol}$ potassium phosphate $\mathrm{pH} 8 \cdot 0 ; 40 \mu \mathrm{mol} \mathrm{L}$-threonine; $0^{\circ} \mathrm{I} \mu \mathrm{mol}$ pyridoxal-5-phosphate. For controls, enzyme was added after termination of the reaction. Dihydroxyacid dehydrase was assayed as described by Kiritani \& Wagner (1970). The reaction mixture contained (per $0.5 \mathrm{ml}$ ): $50 \mu \mathrm{mol}$ potassium phosphate $\mathrm{pH} 8.0$; I5 $\mu \mathrm{mol}$ dihydroxyisovalerate; $4 \mu \mathrm{mol} \mathrm{MgCl}_{2}$. For controls, enzyme was added after termination of the reaction. Transaminase $\mathrm{B}$ was assayed by the method of Duggan and Wechsler (1973). The reaction mixture contained (per $\mathrm{I} \cdot \mathrm{O} \mathrm{ml}$ ): I00 $\mu \mathrm{mol}$ potassium phosphate $\mathrm{pH} 8 \cdot 0 ; 25 \mu \mathrm{mol}$ L-valine; $20 \mu \mathrm{mol} \alpha$-ketoglutarate; $0 \cdot \mathrm{I} \mu \mathrm{mol}$ pyridoxal-5-phosphate. Valine was omitted from the controls. $\alpha$-Isopropylmalate synthetase was assayed using the DTNB procedure of Calvo, Bartholomew \& Stieglitz (I969). The reaction mixture contained (per $0.5 \mathrm{ml}$ ) $: 50 \mu \mathrm{mol}$ tris $\mathrm{pH} 8 \cdot 0 ; 50 \mu \mathrm{mol} \mathrm{KCl}$; $2.5 \mu \mathrm{mol} \alpha$-ketoisovalerate; I $\cdot 0 \mu \mathrm{mol}$ acetyl CoA; $0.2 \mu \mathrm{mol} \mathrm{MnCl}_{2}$. $\alpha$-Ketoisovalerate was omitted from the controls. Activity of all assays was linear with enzyme concentration under the conditions used. Specific activities of all enzymes are expressed as nmol product formed $/ \mathrm{min} / \mathrm{mg}$ protein. Protein was determined by the method of Lowry et al. (I 95I) with crystalline bovine serum albumin used as a standard.

Isolation of resistant mutants. Analogue-resistant mutants were isolated as described by Chapman \& Hull (1974) except that the cells were spread on to minimal medium plates containing $200 \mu \mathrm{g}$ DL-norvaline/ml.

Paper chromatography of cultural supernatants. Cells were initially grown and harvested as described by Chapman \& Hull (1974). They were washed once with a special minimal medium and used to inoculate $200 \mathrm{ml}$ of special minimal medium in a $400 \mathrm{ml}$ beaker to give an $E_{660}$ of 0.67 . The special minimal medium contained (per litre distilled water):

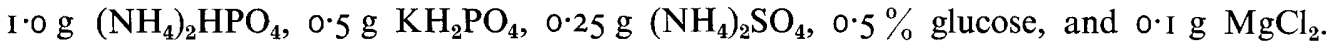
The cells were grown with vigorous stirring at $37^{\circ} \mathrm{C}$ until the extinction reached $2 \cdot 0\left(2 \frac{1}{2}\right.$ to $3 \frac{1}{2} \mathrm{~h}$ ). The $\mathrm{pH}$ of the culture was maintained between 6.6 and $7 \cdot 0$ by adding $\mathrm{NH}_{4} \mathrm{OH}$. The 
cells were removed from the liquid by centrifugation. Twenty-five $\mathrm{ml}$ of the supernatant was desalted using a column of Dowex $50 \mathrm{~W}$ by the procedure of Mueller, Bowman \& Herranen (1955). The eluate containing the amino acids was evaporated to dryness, and the residue resuspended in $\mathrm{I} \cdot 6 \mathrm{ml}$ of $10 \%(\mathrm{v} / \mathrm{v})$ isopropanol.

Paper chromatography was carried out on $22 \times 26 \mathrm{~cm}$ sheets of Whatman No. I chromatography paper. The solvents used were butanol-acetic acid-water (60:15:25, by vol.), phenol-water $(8: 2, \mathrm{w} / \mathrm{v})$, ethanol-water- $\mathrm{NH}_{4} \mathrm{OH}(90: 5: 5$, by vol.), and $t$-butanol-waterethylmethylketone-diethylamine (40:40:20:4, by vol.). Amino acids were located by dipping the dried papers into a solution of $0.2 \%$ ninhydrin in acetone. Colours were allowed to develop for at least $9 \mathrm{~h}$ at room temperature.

Transformation. Transformation procedures were carried out as described by Chapman \& Hull (1974).

Chemicals. TPP, FAD, $\alpha$-ketoglutarate, $\alpha$-ketoisovalerate, acetyl CoA and bovine serum albumin were from Sigma, potassium pyruvate from Calbiochem, DL-norvaline from Nutritional Biochemicals, and sodium $\alpha, \beta$-dihydroxyisovalerate was the gift of Dr H. E. Umbarger, Purdue University, U.S.A.

\section{RESULTS}

\section{Isolation of resistant mutants}

In an effort to obtain mutants of $B$. subtilis derepressed for acetohydroxyacid synthetase, a large number of branched-chain amino acid analogues were screened for their ability to inhibit growth of wild-type cells. Of these, DL-norvaline proved inhibitory. Using a concentration of $200 \mu \mathrm{g} / \mathrm{ml}, 50$ mutants resistant to growth inhibition were then isolated. All were assayed for acetohydroxyacid synthetase, and 20 were derepressed. Four independent isolates (NV2O, NV26, NV35 and NV45) showing different degrees of derepression were selected for further study.

\section{Excretion of amino acids by the mutants}

During isolation of the mutants it was noticed that some of the resistant colonies appearing on analogue-containing plates were surrounded by zones of background growth. This phenomenon often indicates that the mutant is overproducing and excreting a compound which can reverse the inhibitory action of the analogue, allowing growth of sensitive cells. In order to test this hypothesis, the wild-type strain and each NV strain were streaked first parallel to and then away from each other on analogue-containing plates. Growth of the wild-type strain occurred only where it had been streaked adjacent to the mutant strain. All four NV mutants were able to promote the growth of the wild-type strain, although NV2O was less able than the other three strains. These results, therefore, suggest that the resistant mutants excrete a compound or compounds which can reverse the inhibitory effect of norvaline.

The initial approach to identifying the excreted compound(s) was to perform crossfeeding experiments. The resistant mutants were tested for their ability to promote the growth of strains SB7 $\left(\mathrm{Ile}^{-}\right), \mathrm{SB} 377 \mathrm{R}\left(\mathrm{Ile}^{-}, \mathrm{Val}^{-}\right)$and SB27I $\left(\mathrm{Leu}^{-}\right)$when the resistant and auxotrophic strains were streaked parallel to each other on minimal medium plates. With strain $\mathrm{SB} 377 \mathrm{R}$ the experiments were also done using minimal medium + isoleucine and minimal medium + valine. As controls, the auxotrophs were streaked adjacent to the wildtype strain. The wild-type strain did not feed any of the auxotrophs. With the NV mutants only slight cross-feeding was observed with strains SB7, SB377 $R$ on minimal medium, and SB377 R on minimal medium + valine. However, considerable growth of strains SB27 I and 
74<smiles>c1ccccc1</smiles>

80

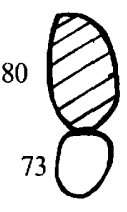

$52 \bigcirc$

30<smiles>[AlH2]</smiles>

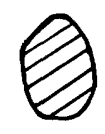

81

73

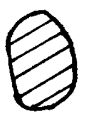

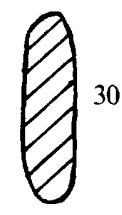<smiles>c1ccc2ccccc2c1</smiles>

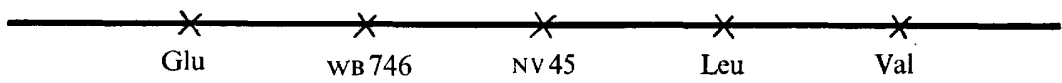

Fig. I. Tracing of a paper chromatogram of the cultural supernatants of strains wB 746 and NV45 along with several amino acid standards. The solvent system used was phenol-water. Concentrates of cultural supernatants were prepared as described in Methods. Striped circles indicate intense ninhydrin-positive spots, and open circles indicate faint ninhydrin-positive spots.

$\mathrm{SB} 377 \mathrm{R}$ on minimal medium + isoleucine occurred when they were streaked next to the resistant mutants. The cross-feeding characteristics of all the NV mutants were similar, which suggests that the mutants may excrete leucine and valine.

The second approach used to identify excreted amino acids was paper chromatography of culture supernatants. Figure I presents a tracing of a chromatogram of the supernatants of NV45, WB746 and several amino acid standards run in phenol-water. Mutant NV45 showed an intense ninhydrin-positive spot having an $R_{F}$ value of 33 , whereas WB746 showed only a weak spot at this point. These spots co-chromatographed with glutamate. Both strains showed weak spots with an $R_{F}$ of 52 (co-chromatographing with alanine). Weak spots with $R_{F}$ values of 73 to 74 , which ran with valine, were also observed. However, NV45 showed an intense spot having an $R_{F}$ value of 80 which was not shown by strain wB746. This spot chromatographed with leucine. Results consistent with these were also obtained with the solvents butanol-acetic acid-water, ethanol-water- $\mathrm{NH}_{4} \mathrm{OH}$, and $t$-butanol-water-ethylmethylketone-diethylamine. Qualitatively, all of the mutants gave 
Table I. Enzyme levels in the norvaline-resistant mutants

Growth of cells, preparation of extracts and assay of enzymes were described in Methods.

Specific activity $/ \mathrm{nmol}$ product formed $/ \mathrm{min} / \mathrm{mg}$ protein

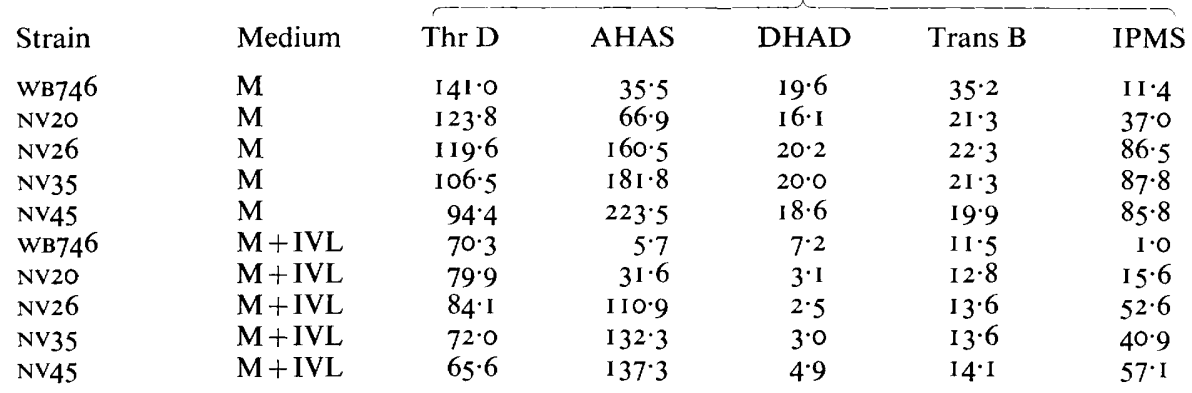

M, minimal medium; I, isoleucine $(50 \mu \mathrm{g} / \mathrm{ml}) ; \mathrm{V}$, valine $(50 \mu \mathrm{g} / \mathrm{ml}) ; \mathrm{L}$, leucine $(40 \mu \mathrm{g} / \mathrm{ml}) ; \mathrm{Thr} \mathrm{D}$, threonine deaminase; AHAS, acetohydroxyacid synthetase; DHAD, dihydroxyacid dehydrase; Trans B, transaminase B; IPMS, isopropylmalate synthetase.

similar results. Quantitatively, however, there were some variations among the four mutants as well as between different supernatants of the same mutant. Strain NV20 showed the weakest accumulation. Some supernatants showed only a weak spot corresponding to glutamate. However, with three supernatants of the wild-type strain, either no spot or only a very weak spot chromatographing with leucine was ever observed. The chromatographic experiments therefore support the results of the cross-feeding experiments, that the mutants excrete leucine and possibly valine.

\section{Enzyme levels in the resistant mutants}

The specific activities of a number of the branched-chain amino acid biosynthetic enzymes were determined and compared with those present in the wild-type strain (Table I). When grown in minimal medium, NV20 was derepressed about two-fold for acetohydroxyacid synthetase, NV26 and NV35 about 4.5- to 5-fold, and NV45 about sixfold. When the strains were grown in minimal medium plus excess isoleucine, valine and leucine, some repression of enzyme synthesis occurred in all the mutants, but not to the extent that it occurred in WB746. On the other hand, threonine deaminase, dihydroxyacid dehydrase and transaminase B were not derepressed in any of the mutants. Supplementation of the medium with isoleucine, valine and leucine resulted in complete repression of these three enzymes. However, the first leucine enzyme, $\alpha$-isopropylmalate synthetase, was derepressed in all of the mutants, NV2O about three-fold and the other strains about $7 \cdot 5$-fold. As observed with acetohydroxyacid synthetase, growth of the cells in the presence of isoleucine, valine and leucine resulted in only partial repression of enzyme synthesis. None of the mutants showed significant alterations in the extent of feedback inhibition of threonine deaminase by isoleucine, acetohydroxyacid synthetase by valine or of $\alpha$-isopropylmalate synthetase by leucine.

\section{Preliminary genetic mapping}

Linkage of norvaline resistance to the leucine operon was tested by determining the cotransfer of mutant loci with the leucine marker of strain SB27I in a repulsion cross of the type $n o v^{r} l e u^{+}$(donor) $\times n o v^{8} l e u^{-}$(recipient). The resistance markers in strains NV45 and NV2O showed 10 and $40 \%$ cotransfer, respectively, with the reference marker at limiting DNA 
concentrations. Thus, the gene conferring analogue resistance appears to be carried on the same molecule of transforming DNA as the genes specifying the leucine enzymes.

\section{DISCUSSION}

The four norvaline-resistant mutants examined in this study all appear to have similar properties. Only quantitative differences in the extent of derepression of acetohydroxyacid synthetase and $\alpha$-isopropylmalate synthetase, and in the amounts of excreted amino acids, have so far been observed. It is therefore probable that the mutation in each strain involves the same gene, although more detailed genetic studies will be necessary to confirm this.

No mutants of $E$. coli or $S$. typhimurium resistant to norvaline have been reported. Of the analogue-resistant strains that have been studied, none show a pattern of derepression of the branched-chain amino acid biosynthetic enzymes similar to the norvaline mutants described here. However, Ward \& Zahler (1973a,b) have isolated mutants of B. subtilis resistant to 4 -azaleucine which are derepressed for the leucine enzymes and acetohydroxyacid synthetase. The mutation maps to one side of the leucine operon. Thus, our norvalineresistant strains are phenotypically similar to their azaleucine-resistant mutants, and they may also be similar genetically.

This study was supported by grant GM 20330 from the National Institute of General Medical Sciences, U.S. Public Health Service.

\section{REFERENCES}

Bauerle, R. H., Freundlich, M., Störmer, F. C. \& Umbarger, H. E. (1964). Control of isoleucine, valine and leucine biosynthesis. II. Endproduct inhibition by valine of acetohydroxyacid synthetase in Salmonella typhimurium. Biochimica et biophysica acta 92, I42-I 49.

Calvo, J. M., Freundlich, M. \& Umbarger, H. E. (1969). Regulation of branched-chain amino acid biosynthesis in Salmonella typhimurium: isolation of regulatory mutants. Journal of Bacteriology $\mathbf{9 7}$, I 272-I 282 .

Calvo, T. M., Bartholomew, J. C. \& Stieglitz, B. I. (I969). Fluorometric assay of enzymatic reactions involving acetyl coenzyme $\mathrm{A}$ in aldol condensations. Analytical Biochemistry 28, I 64-I $8 \mathrm{I}$.

Chapman, L. F. (1972). Regulation of acetohydroxyacid synthetase in Bacillus subtilis. Molecular and General Genetics 117, 14-18.

Chapman, L. F. \& Hull, C. J. (1974). Strains of Bacillus subtilis synthesizing elevated levels of isoleucinevaline biosynthetic enzymes. Molecular and General Genetics 129, 87-95.

Duggan, D. E. \& Wechsler, J. A. (1973). An assay for transaminase B activity in Escherichia coli KI 2. Analytical Biochemistry 5ז, 67-79.

Hatfield, G. W. \& UMbarger, H. E. (I97I). L-Threonine deaminase, biosynthetic (Bacillus subtilis). In Methods in Enzymology 17 B, 561-566. Edited by H. and C. W. Tabor. New York and London: Academic Press.

Kiritani, K. \& WAGNeR, R. P. (I970). $\alpha, \beta$-Dihydroxyacid dehydrase (Neurospora crassa and spinach). In Methods in Enzymology I7A, 755-764. Edited by H. and C. W. Tabor. New York and London: Academic Press.

Lowry, O. H., Rosebrough, N. J., Farr, A. L. \& Randall, R. J. (I95I). Protein measurement with the Folin phenol reagent. Journal of Biological Chemistry $\mathbf{r 9 3}, 265-275$.

Mueller, G. C., Bowman, G. \& Herranen, A. (1955). Desalting amino acid solutions by ion exchange. Analytical Chemistry 27, 1357-1358.

Szentirmai, A., Szentirmai, M. \& Umbarger, H. E. (1968). Isoleucine and valine metabolism of Escherichia coli. XV. Biochemical properties of mutants resistant to thiaisoleucine. Journal of Bacteriology 95 , $1672-\mathrm{I} 679$.

WARD, J. B. \& ZAHLER, S. A. (1973a). Genetic studies of leucine biosynthesis in Bacillus subtilis. Journal of Bacteriology I16, 719-726.

WARD, J. B. \& ZAHLeR, S. A. (1973b). Regulation of leucine biosynthesis in Bacillus subtilis. Journal of Bacteriology II6, 727-735.

Westerfield, W. W. (I945). A colorimetric determination of blood acetoin. Journal of Biological Chemistry r6r, 495-500. 